\title{
Brittle Fracture of Dental Amalgam
}

\author{
KAMAL ASGAR and LLOYD SUTFIN \\ University of Michigan, Schoot of Dentistry, Ann Arbor, Michigan
}

The brittleness of dental amalgam limits its use to sites in which tensile stresses can be kept at a minimum. If the cause for the brittleness could be ascertained, then an approach to correct this problem could be devised.

Physical properties of metals are ultimately manifested in, and can be explained by, their microstructure. Through the work of several researchers, ${ }^{1-3}$ means of identifying the phases present in the microstructure have been developed. In this study, the etching solutions developed by Schmitt ${ }^{1}$ and Wing $^{2}$ were employed. The phases present in amalgam, as shown by these chemical etches, are identified as $\gamma, \gamma_{1}$, and $\gamma_{2}$. The $\gamma$ phase comprises most of the original particle which remains after the reaction of $\mathrm{Hg}$ with the amalgam alloy. The $\gamma_{1}$ phase is the reaction product of mercury with silver present in the original particle and is identified as $\mathrm{Ag}_{2} \mathrm{Hg}_{3}$. This phase forms a matrix about the $\gamma$ phase. Interspersed in this matrix also are small islands of the $\gamma_{2}$ phase, which is formed by reaction of mercury with the tin contained in the original particle. Copper and zinc are also present, but neither their nature nor their location has been established. Therefore, the microstructure of amalgam is known in a general way only.

Observing the microstructure of an alloy under stress, with the Flinn strain-viewer, ${ }^{4}$ has been applied to dentistry by observance of crack propagation in cobalt-base and gold alloys. ${ }^{5}$ However, the same procedure cannot be applied directly to amalgam as cracking occurs instantaneously. A technique was devised which avoids the problem of brittleness and permits the structure to be observed during crack propagation.

\footnotetext{
Presented before the Dental Materials Group of the IADR at Pitsburgh, $\mathrm{Pa}$., March, 1963.

This investigation was supported by U.S. Public Health Service Research Grant 1-\$01-FR-05021-01 from the National Institute of Dental Research, National Institutes of Health,
Bethesda, Md.

Received for publication June 10, 1964.
}

\section{Materials and Methods}

THEORETICAL CONSIDERATIONS... The Flinn strain-viewer is so designed that the specimen, in the form of a beam, is restrained from any movement other than pure bending. The convex side of the beam undergoes tension and the concave side undergoes compression. A plane exists within the beam where neither occurs. This plane is known as the neutral surface. By mounting the beam in the strain-viewer, the effect of these various strains on the microstructure can be observed through the microscope.

For a ductile material, this technique works quite well. However, it is impossible to observe crack propagation in amalgam. Therefore, the concept of two-phase materials was applied to restrict crack propagation.

In two-phase materials, a strong, rigid material is matched with a weaker, but more ductile, material. The ductile material absorbs the strain energy released when an individual fiber of the brittle material fails and transfers the stresses to the remaining fibers of the brittle phase. This concept indicates that crack propagation in a composite beam consisting of a brittle bar surrounded by a ductile material should be retarded.

The location of the neutral axis of such a beam consisting of two materials can be altered by changing the ratio of the heights of each component of the beam. Simon ${ }^{6}$ has discussed this matter and has been able to calculate mathematically the location of the neutral axis of a composite beam for any shape of specimen. From his equations, formulas were derived to select a suitable plastic and to estimate the dimensions of the composite beam. The total depth of the beam is found using the formula

$$
\begin{aligned}
& P=n \\
& \mp \sqrt{n^{2}-\left(\frac{E_{a}}{E_{p}}-1\right)(D+T-2 n)(D-T),}
\end{aligned}
$$


where $P$ equals total depth of composite beam; $n$, distance to neutral axis from base; $E$, Young's modulus (slope of the stressstrain curve); $D$, distance from compression edge of a composite beam to tension edge of brittle material; $T$, depth of plastic on compression side; $a$ (subscript), brittle material (amalgam); and $p$ (subscript), ductile material (plastic). (See Fig. 1 for diagram.)

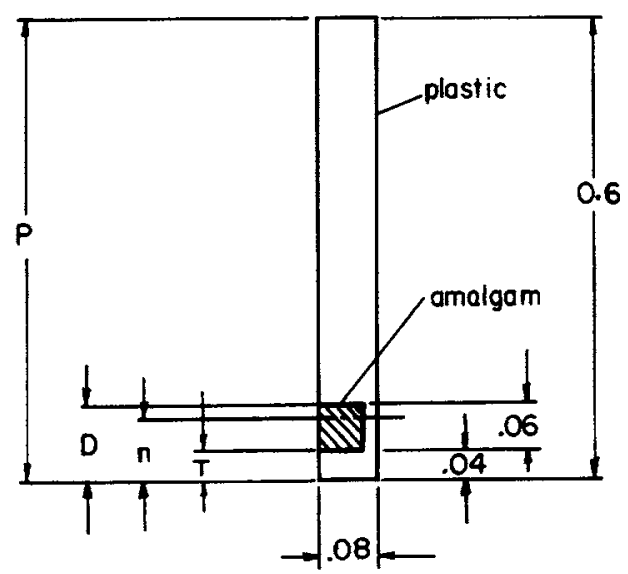

Fig. 1.- Symbols and dimensions of the composite beam.

The strength of the plastic must be suffcient to allow the amalgam beam to fail first, even though it is located closer to the neutral axis of bending. The following equation enables one to select a plastic that has sufficient strength:

$$
S_{p}(\max )=\frac{(P-n)}{(D-n)} \frac{E_{p}}{E_{a}} S_{a} \text { (ultimate) }
$$

where $S$ equals stress. If $S_{p}$ (maximum) is less than $S_{p}$ (ultimate), then the amalgam will fail first. The derivation of these equations is reported by Sutfin and Asgar. ${ }^{7}$

It should be noted that the modulus used for a self-curing plastic is the slope of the stress-strain curve at a strain equal to the setting contraction plus the strain applied during the test. These equations gave good results when beams were prepared approximately to the calculated dimensions.

TECHNIQUe.--The beams were prepared from a typical amalgam alloy. ${ }^{*}$ The material was amalgamated using a mechanical amal-

* Caulk's 20th Century Fine-Cut Alloy, L. D. Caulk Co., Milford, Del. gamator, $\uparrow$ a steel capsule and pestle. Mercury-to-alloy ratios of $8: 5$ and $6.5: 5$ were used, and the trituration time was $12 \mathrm{sec}-$ onds. Excess mercury was expressed using a squeeze cloth and pliers. The beams were packed with a $1-\mathrm{mm}$.-diameter plugger in a three-piece steel die which produced a small bar with $\frac{1}{16}{ }^{\prime \prime}$ square cross-section and $1 \frac{1}{16}$ " length. Figure 2 is an exploded-view drawing of the die. Fifteen minutes after the finish of condensation, the beams were removed from the die and allowed to harden for at least 24 hours before being imbedded in plastic.

The beams were potted in a self-curing plastic $\ddagger$ which was allowed to harden at room temperature for at least 2 days before metallographic polishing. After polishing, the potted beams were cut to form a composite beam of dimensions as shown in Figure 1.

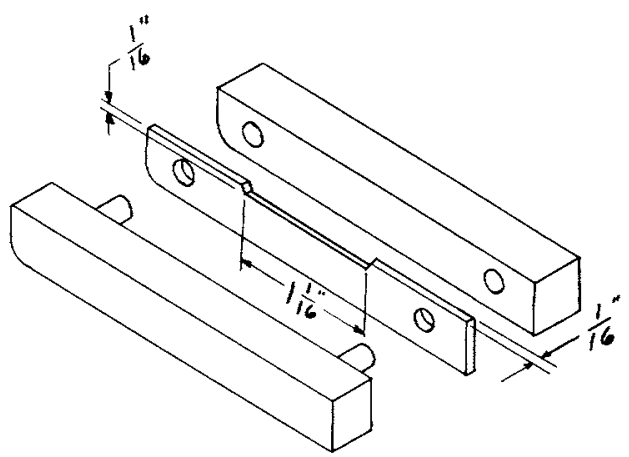

FIG. 2.-Exploded diagram of steel die

Figure 3 shows a composite beam mounted in the Flinn strain-viewer. This device was used to stress the beam in bending and has been fully described by Flinn and Trojan. ${ }^{4}$ The viewing slot was enlarged to permit the use of the wide beam and the high power objective of the microscope, as shown in Figure 3, $B$.

The load was applied slowly to the beam, and it was scanned for evidence of failure, which occurred in about 30 minutes. The first signs of stress were several small unconnected cracks. These occurred in areas other than that in which the major crack appeared.

† S. S. White Mechanical Amalgamator, S. S. White Dental Manufacturing Co., Philadelphia, Pa.

$\ddagger$ Ward's Bioplastic, Ward's Natural Science Establishment, Rochester, N.Y. 


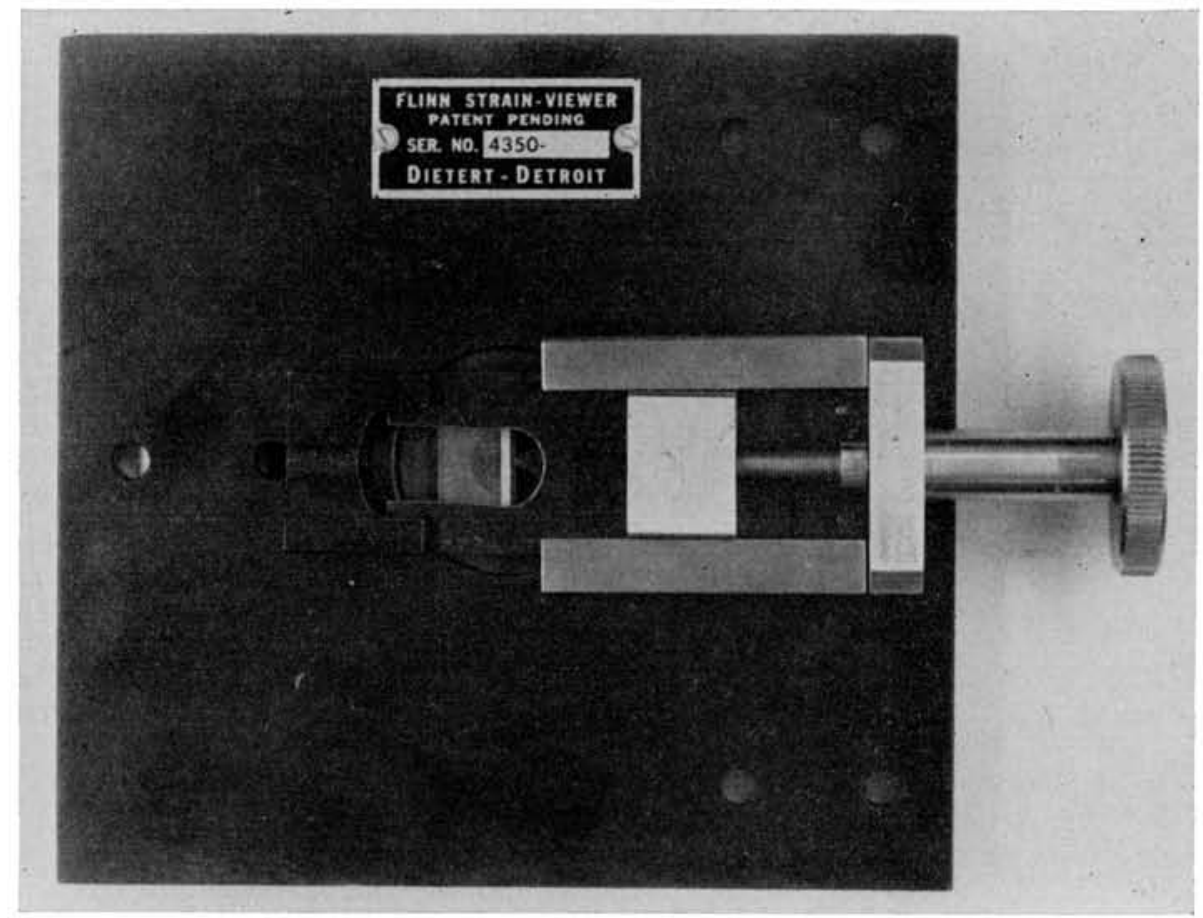

$A$

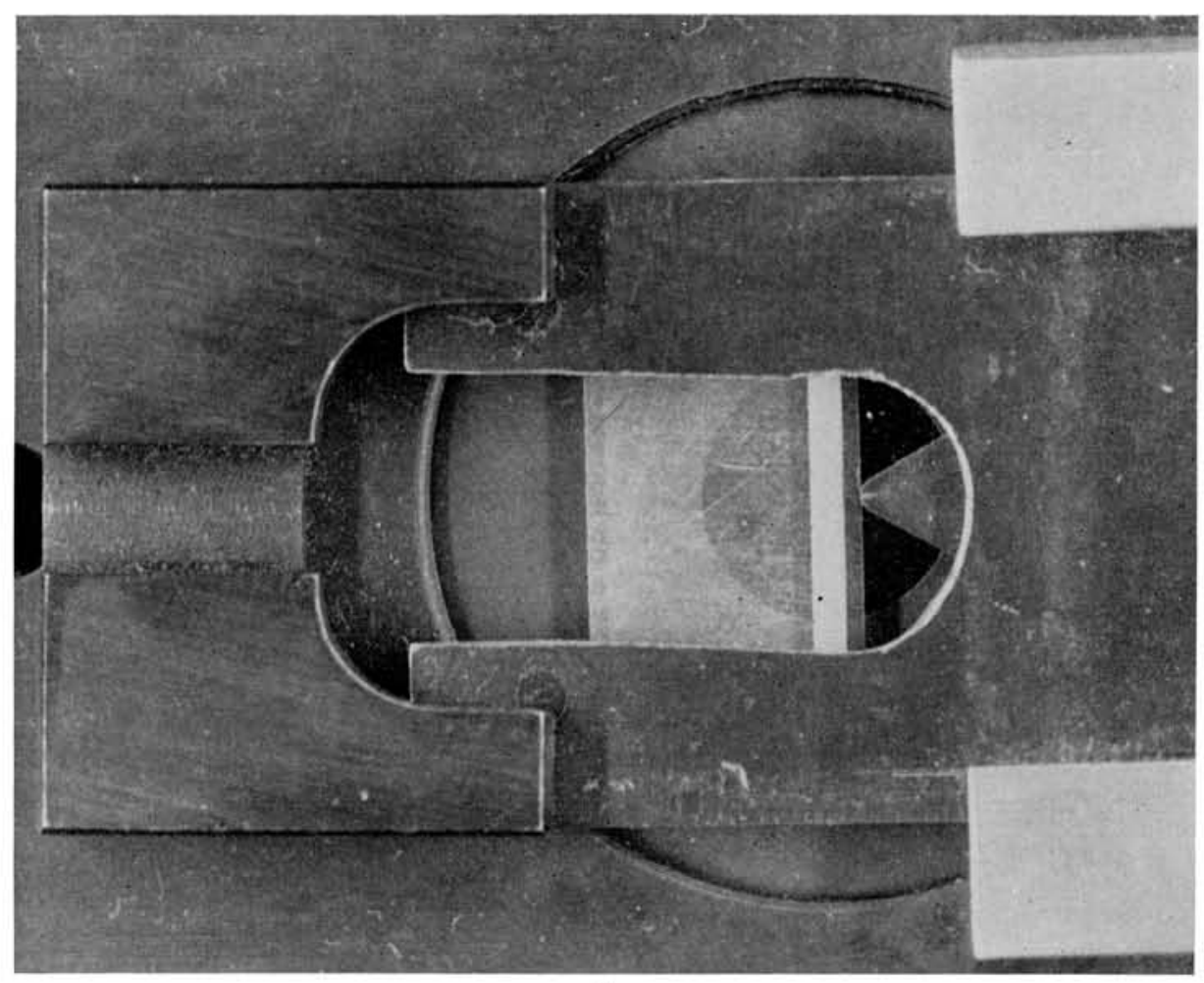

B

Fig. 3. $-A$, Composite beam mounted in Flinn strain-viewer. $B$, Higher magnification of the mounted beam. 
After the initial failure was observed, the beam was removed from the fixture, etched to reveal the grain structure, remounted in the fixture (permanent deformation of the plastic provided seats for realigning the specimen in the fixture), and photographs were taken of the etched samples. Etching was not done until after cracking to avoid influencing the manner of failure.

The etching solutions used were the ferric chloride etch developed by Schmitt ${ }^{1}$ and the cyanide etch developed by Wing. ${ }^{2}$ The effects of these etches on amalgam are shown in Figure 4 and 5 with the phases identified.

\section{Results and Discussion}

During the bending of a beam, the maximum compressive stresses or maximum ten- sile stresses occur in the outermost fibers. That is to say, stress on the fibers increases as the distance from the neutral axis also increases. Using the technique devised for this study, the neutral axis was not in the middle of the amalgam specimen but instead was about one-fourth of the thickness from the tension edge. Therefore only one-fourth of the amalgam specimen was under tension and the remaining three-fourths under compression. In this manner, the magnitude of the tensile stress placed on the amalgam specimen was much less than that of the compressive stress. The crack originated on the tensile side. Figure 6 is representative of the extent of the initial crack. As the deformation was increased, the crack lengthened but usually became completely ar-

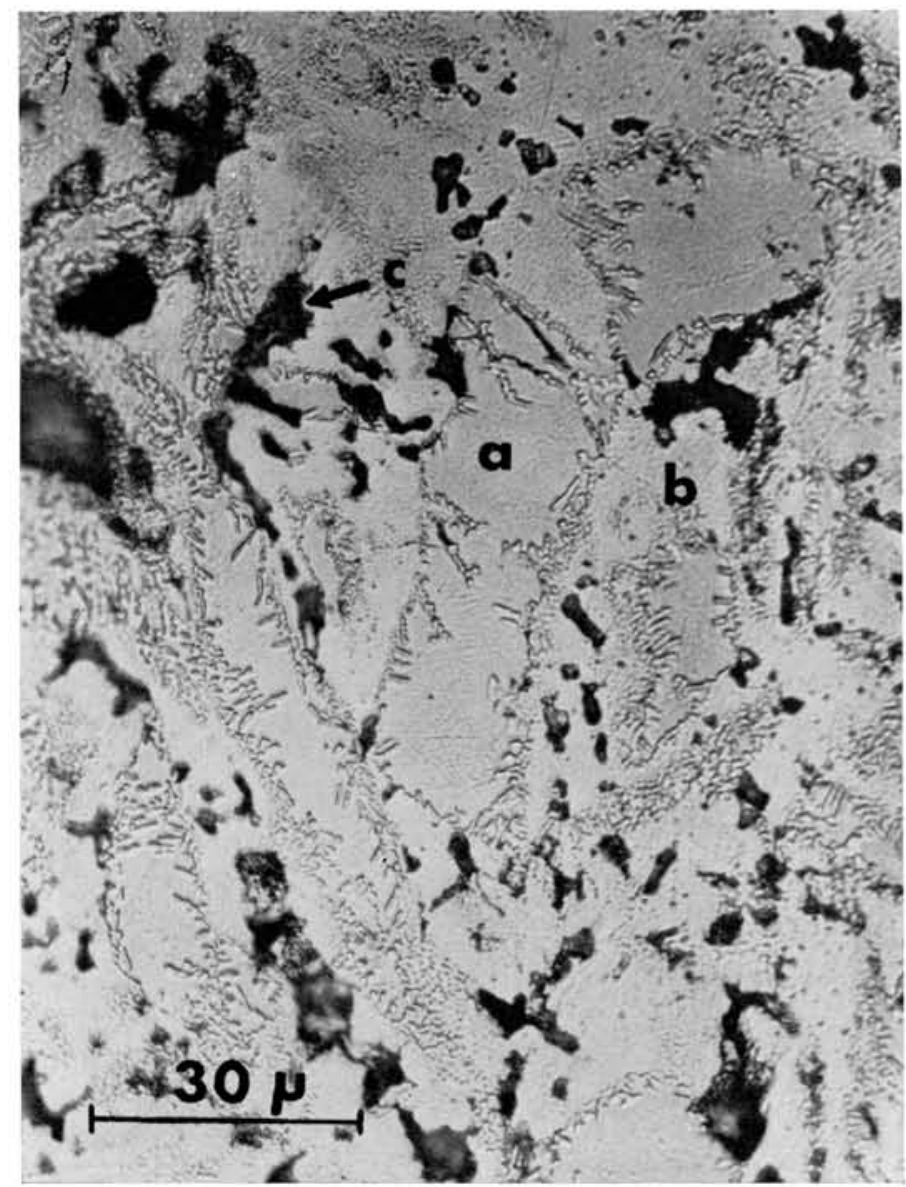

FIG. 4.-Amalgam etched with ferric chloride etch. $a, \gamma ; b, \gamma_{1} ; c, \gamma_{2}$ or void 
rested about halfway through the amalgam. Another crack originated from the compression side to complete the failure.

Figure $7, A$, shows the start of a crack in an unetched beam. Figure $8, A$, shows its continuation and a second crack which began on the compression side and worked toward the tension side. Figures $7, B$, and $8, B$, show the same areas after the specimen was etched with the ferric chloride etch. A higher magnification of the start of the crack is shown in Figure 9, $A$ and $B$.

Analysis of these photomicrographs indicates the crack passes most frequently through voids, $\gamma_{2}$ phase, and $\gamma_{1}$ phase. The $\gamma$ phase is most resistant to failure. Usually the crack goes around the $\gamma$ phase; in none of the specimens does the crack originate in the $\gamma$ phase. However, when the crack is almost one-half the depth of a beam and meets a $\gamma$ phase, the direction does not change to go around the phase. Here the crack goes through the $\gamma$ phase, which appears to be fractured at grain boundaries or along slip planes (Fig. 8).

Figures $10, A, 10, B, 11, A$, and $11, B$, show the path of a crack through another amalgam beam. Here the cyanide etch was used. Since this etch reveals the grain boundaries of the $\gamma_{1}$ phase, the actual path of the crack through this phase can be noted. (Also note the very small grain size and pronounced grain boundaries.) The irregular path of this crack can be explained by observing the $\gamma_{1}$ grain boundaries. When no voids or $\gamma_{2}$ phases are available for passage of the crack, it goes along the grain boundaries of the $\gamma_{1}$ phase. This type of failure is described as intergranular and is characteristic of brittle materials.

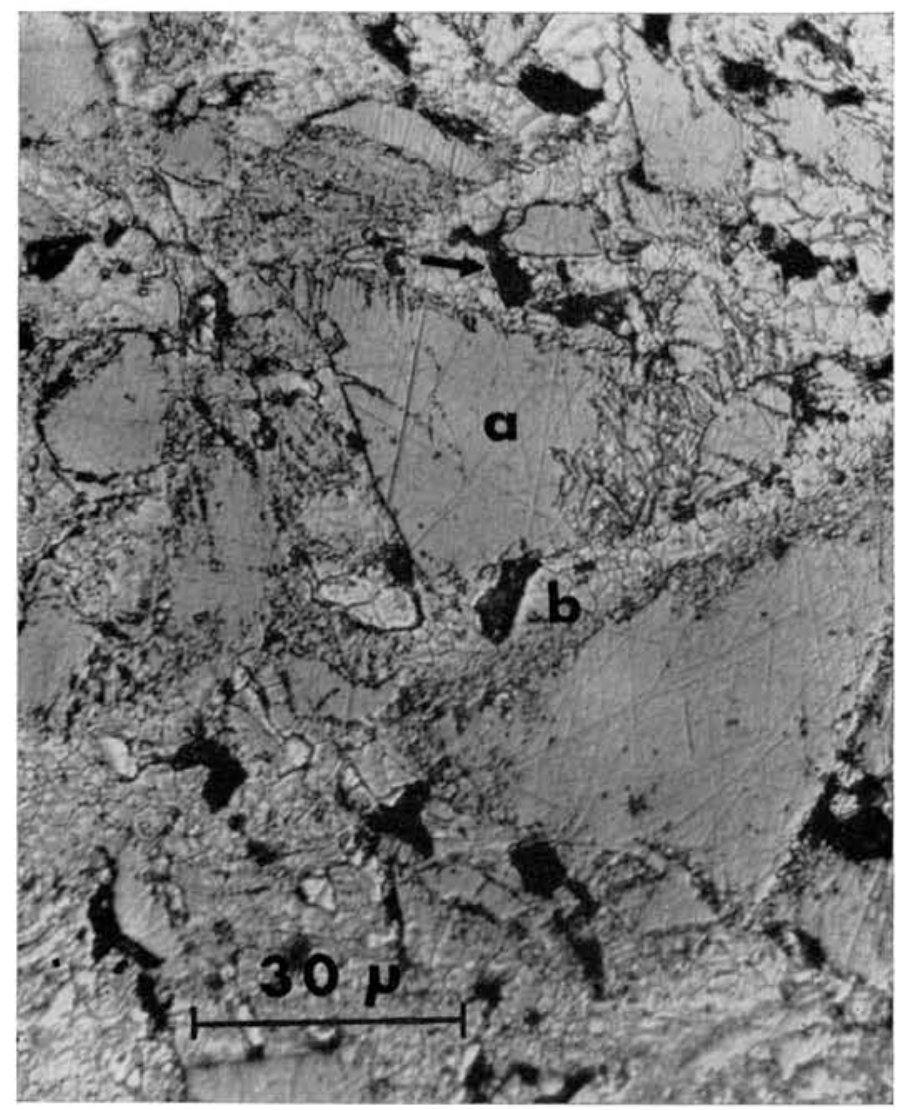

FIG. 5.-Amalgam etched with cyanide etch. $a, \gamma ; b, \gamma_{1} ; c, \gamma_{2}$ or void 
The results of this study become significant when the possible causes of brittleness, of intergranular failure, of very pronounced grain boundaries revealed by etching, and of very small grain size are considered. Brittleness and intergranular failure are closely related and have been shown to be caused by segregation of impurities at grain boundaries in other alloy systems. ${ }^{8}$ Also a high degree of chemical activity (etching) at grain boundaries has been related to the segregation of impurities at the grain boundary as well as to the distortion of the crystal structure which occurs there. ${ }^{8}$ Although the mechanical mixing with which the mercury and alloy are amalgamated would tend to produce a large number of grains, a high concentration of impurities of the type suitable for the formation of nucleation centers can also produce a large number of grains. ${ }^{9}$ Dental amalgam, therefore, exhibits several characteristics of an alloy which contains a significant amount of impurity, and there is evidence to indicate that this impurity is segregated at grain boundaries of the $\gamma_{1}$ phase.

\section{Summary}

A technique for studying the relationship of tensile strength to the microstructure of dental amalgam has been developed. Application of the concept of two-phase materials allowed the microscopic observation of the path of the cracks induced by bending stresses. In order of the ease of penetration, the crack goes through the voids and $\gamma_{2}$ phase, through the grain boundaries of the $\gamma_{1}$ phase, around the $\gamma$ phase, and then through the $\gamma$ phase.

The results of this experiment, although not conclusive, indicate that the properties of dental amalgam may be determined by

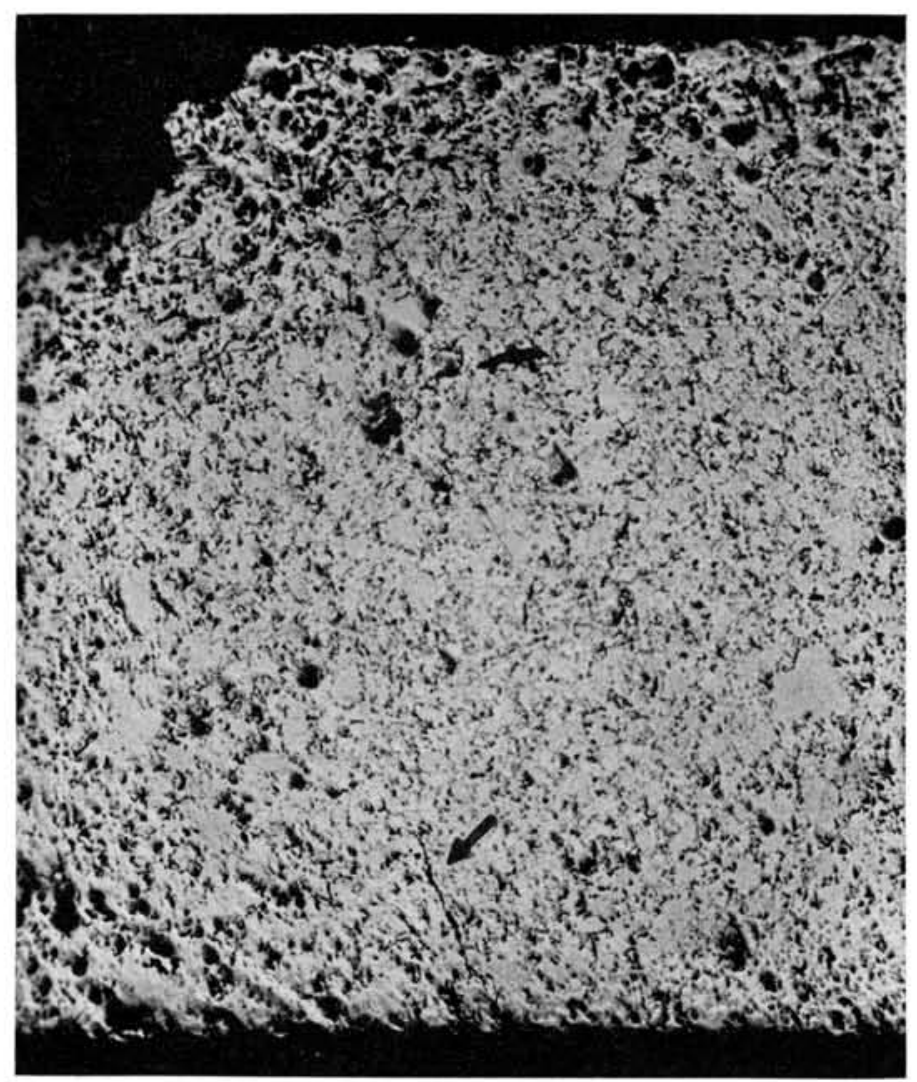

FIG. 6.-Extent of initial crack in unetched beam 

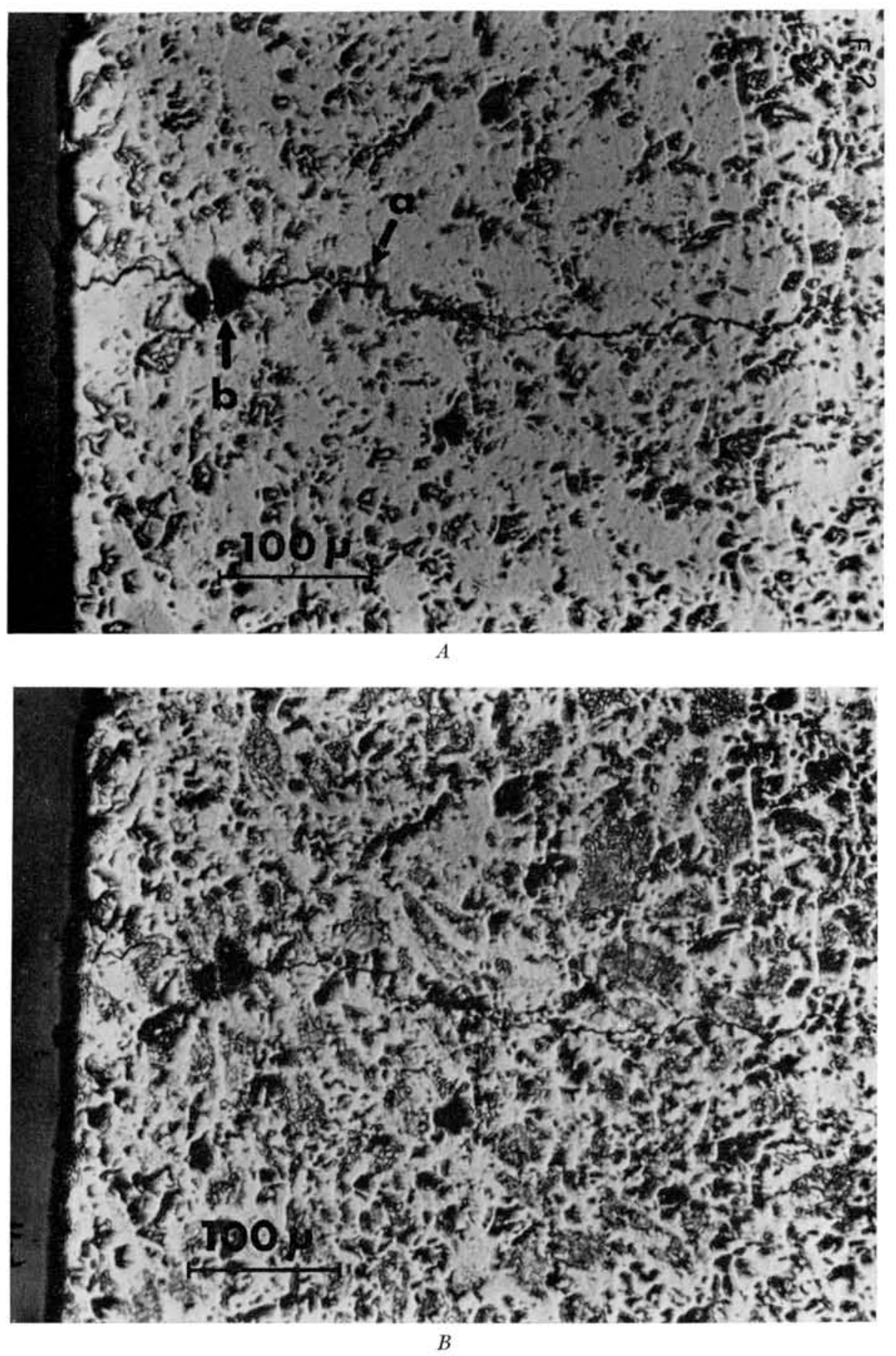

Fig. 7.-A, Start of a crack in an unetched beam: $a, \gamma_{2} ; b$, void. $B$, Same area etched with ferric chloride etch. 

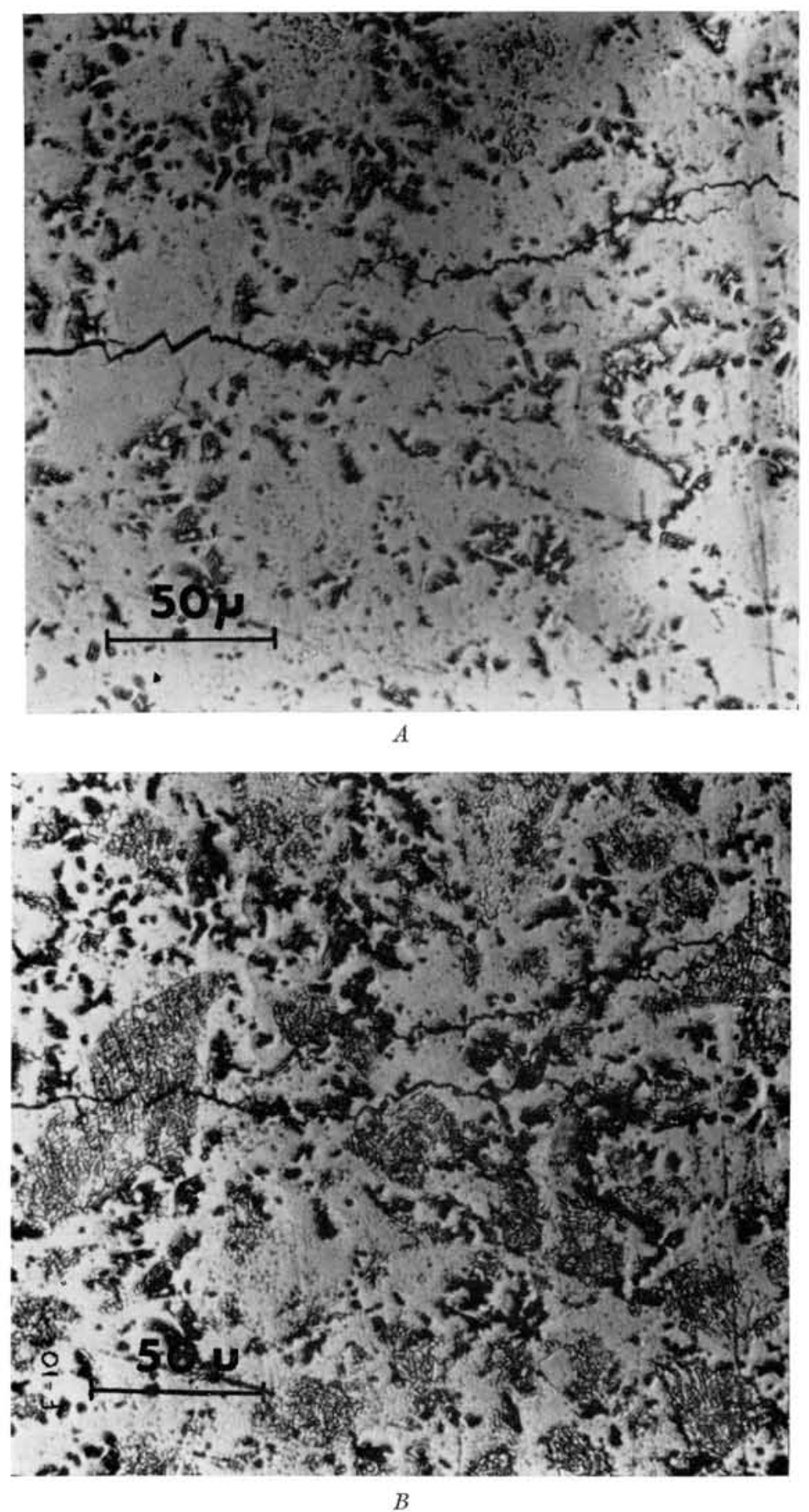

Fig. 8. - A, Continuation of crack shown in Fig. 7. Unetched, $B$, Same area etched with ferric chloride etch. 


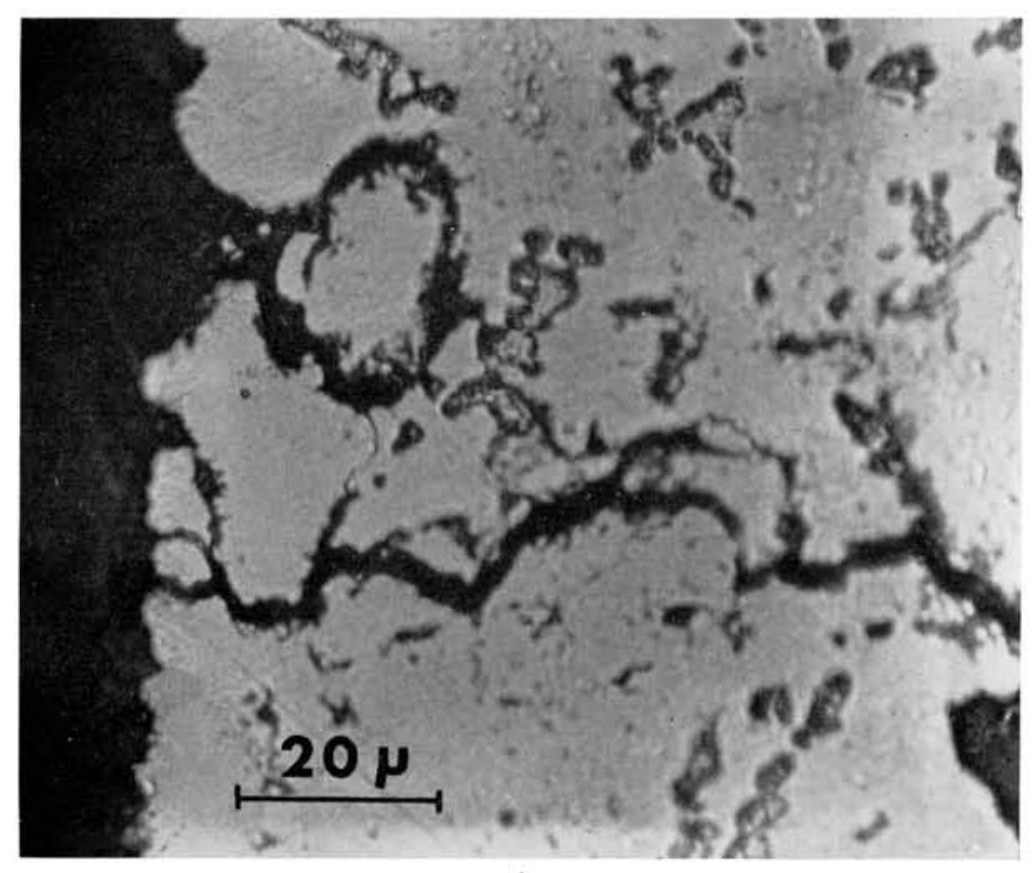

A

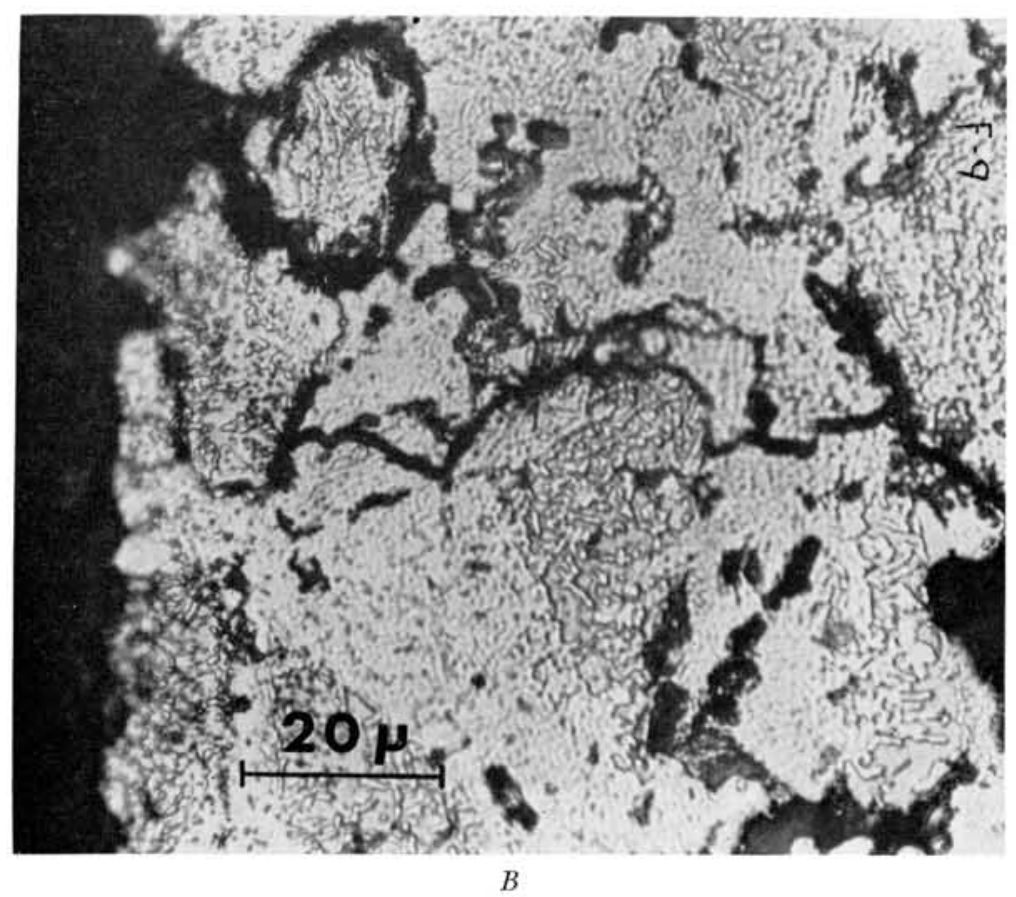

FIG, 9.-A, Higher magnification of the start of the crack shown in Figs. 7 and 8. Unetched. $B$, Same area etched with ferric chloride etch. 

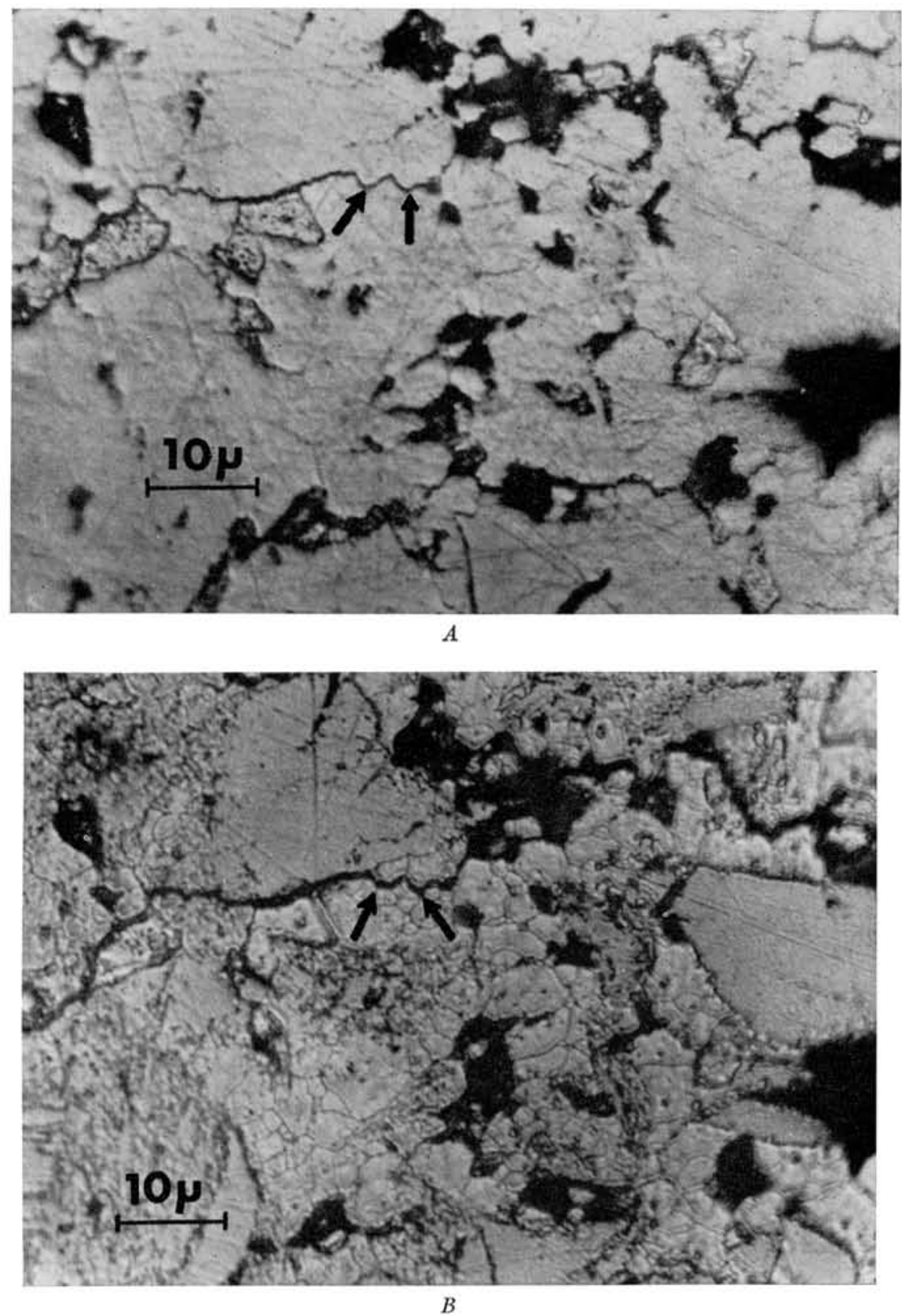

Fig. 10. $-A$, Path of a crack through another beam. Unetched. $B$, Same area etched with cyanide. Arrows point to $\gamma_{1}$ grain boundaries. 

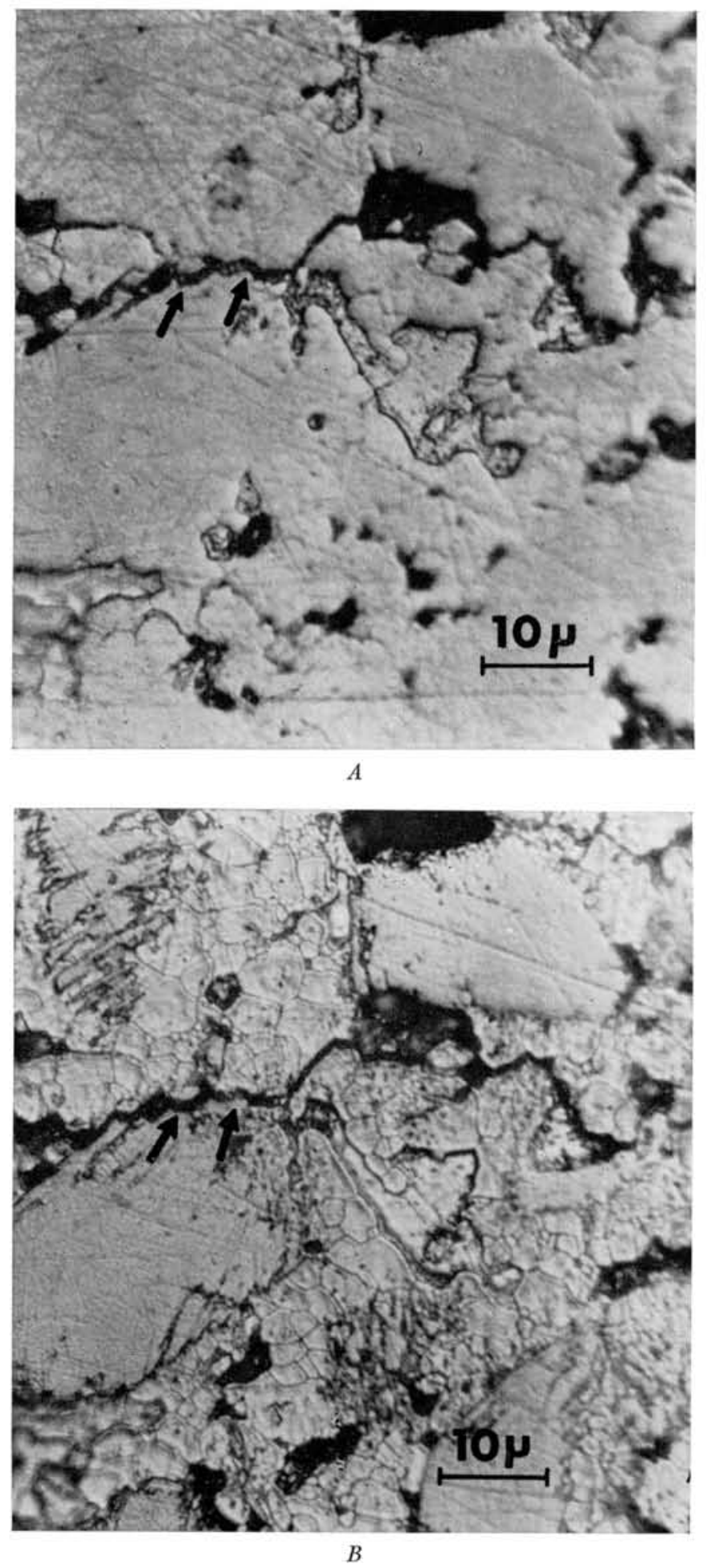

Fig. 11. $-A$, Another portion of the crack shown in Fig. 10. Unetched. B, Same area etched with cyanide etch. Arrows point to $\gamma-\gamma_{1}$ interface. 
the impurities segregated at the grain boundaries of the matrix. This is a promising place to begin further research.

\section{References}

1. Schmit, G. Über das Gefüge von Amalgamfüllungen verschiedener Zusammensetzung und Herstellung, Disch. zahnärzll. Z., 15: 736-51, 1960.

2. WrNG, G. The Microscopic Structure of Dental Amalgam. Paper presented at 1963 IADR meeting (microfilm).

3. Smith, D. I., Ferguson, G. W., and Schoonover, I. C. Microstructure of Dental Amalgam, J. Amer. dent. Ass., 47:305-11, 1953.

4. Finn, R. A., and Trojan, P. K. Simple Equipment
Opens Research Door, Modern Castings and Am. Foundryman, 28:62-65, 1955.

5. Asgar, K. and Peyton, F. A. Flow and Fracture of Dental Alloys Determined by a Microbend Tester, $J$. dent. Res., 41:142-53, 1962.

6. Srmon, A. W. Theory of Beams Composed of Two Elastic Materials, Amer. J. Physiol., 7:500-502, 1959.

7. Sutrin, L. V., and Asgar, K. Two Phase Concept Used To Study Brittle Failure Microscopically, ASM Trans. Quart., 57: 749-53, 1964.

8. CAHN, R. W. Grain Boundaries, Substructures, and Impurities. In Impurities and Imperfections, ed. $0 . \mathrm{T}$. Marzke, pp. 41-83. Cleveland, Ohio: American Society for Metals, 1955.

9. Chalmers, B. Effects of Impurities and Imperfections on Crystal Growth. In Impurities and Imperfeclions, ed. O. T. Marzke, pp. 84-106. Cleveland, Ohio: American Society for Metals, 1955. 